\title{
The Application and Function of Multimedia Technology in Vocal Music Teaching in Colleges and Universities
}

\author{
Li Shan \\ Nanjing Institute of Visual Arts, Nanjing, Jiangsu, China, 211215
}

Keywords: College Vocal Music, Multimedia Technology, Classroom Teaching, Application and Function

\begin{abstract}
With the rapid development of information technology in recent years, multimedia technology has also been rapid development, Internet technology has penetrated into people's daily life, work and learning to come, in this context, college vocal teachers should pay attention Live opportunities face to meet the challenges, give full play to the advantages of multimedia technology, and constantly innovate the mode of teaching vocal music to enhance the efficiency of practical teaching. Vocal music itself is an art, which shows that vocal music teaching also need to obey a certain aesthetic consciousness, the pursuit of aesthetics is the principle of vocal music teaching for teachers have a high demand and standards, so in the actual vocal teaching process, the vocal It is imperative to carry out teaching reform. Teachers need not only to constantly improve their professionalism, but also pay attention to enhance their own information technology capabilities. This paper analyzes and probes into the application and function of multimedia technology in vocal music teaching in colleges and universities, and effectively solves the problems in the teaching of vocal music in colleges and universities, and promotes the development of vocal music teaching in colleges and universities.
\end{abstract}

\section{Introduction}

Vocal music itself has a difficult to learn, and more difficult to teach the characteristics of the teaching of vocal music is necessary to rely on their own control to complete the consciousness, through the teachers will emphasize to the students to find the location, looking for feeling, and these are touched and see but also to the college vocal music teaching has brought great difficulty. In the traditional vocal music teaching, teachers are almost by virtue of their own experience and feel to teach, then in this mode of teaching, usually teaching and students need to pay a greater physical cost, in the classroom teaching often need students repeated practice to be able to find the appropriate feeling. The teacher will use multimedia technology in vocal music teaching, can use advanced technology to solve the difficult problem of vocal music teaching, effectively active classroom teaching atmosphere, and constantly improve the efficiency and quality of college vocal music teaching, and truly realize the comprehensive development of students.

\section{The Application of Multimedia Technology in Vocal Music Teaching in Colleges and} Universities

It Is Decided by the Current Situation and the Problem of Chinese Music Teaching. At present, the teaching of vocal music in our country is still relatively backward compared with that of the western countries. It is because the foundation of music education in our country is relatively weak, and the development of international music education is developing rapidly. This leads to the current development of vocal education in our country facing many challenges. Nowadays, the trend of global integration and cultural diversification of human society is becoming more and more obvious. At present, any country and nation cannot talk about their own development and need to 
observe the global vision [1]. Therefore, the current vocal education of colleges and universities, need to fully consider the development of music education in today's international world background, in multimedia teaching to solve the multi-cultural values and other major issues. As the current market for the needs of modern music talent, colleges and universities in the vocal music teaching philosophy is also constantly reform and innovation, hoping to effectively make up for their own shortcomings, better play the characteristics and expertise of students. The relevant departments of the country also stressed the emphasis on the application of modern educational means to cultivate modern scientific and technological personnel, but in fact our college vocal teachers, there are still a considerable part of the teachers for the lack of computer knowledge ability, combined with the current problems, the combination of multimedia teaching in college music teaching is a necessity.

It Is the Objective Requirements of Chinese Socialist Modernization. At present, the teaching work in our country needs to deepen the reform of educational thoughts, contents and methods, to solve the phenomenon of social development and economic construction in teaching, to adjust the curriculum structure and to strengthen the basic knowledge, theory and Skills training. At present, the vocal music teaching in colleges and universities needs to carry on the reform and the innovation constantly, and realize the innovation of vocal music teaching in colleges and universities, need to actively use modern science and technology to effectively improve the modern level of vocal education [2]. The teaching of vocal music in our country needs to grasp the opportunity and fully apply the multimedia technology. We should pay attention to keep pace with the times, innovate and make multimedia music teaching more popular and efficient in the teaching of vocal music in colleges and universities. Quality, so that our country vocal music teaching can be more specialized, systematic, scientific and international. With the rapid development of science and technology, information technology has penetrated into all aspects of people's actual life, people entered the digital information age, so in the current college vocal teaching, we should pay attention to the full application of multimedia vocal teaching methods, the development of modernization of vocal music teaching in China.

\section{The Use of Multimedia Technology in the Teaching of Vocal Music in Colleges and Universities}

Extend the Teaching of College Vocal Classroom. In the traditional vocal classroom teaching process, classroom teaching does not have continuity, the general students in the classroom after the end, only by virtue of their own classroom memory to practice then the students in this mode of learning and it is easy to lose the classroom the correct feeling in teaching [3]. The teacher focus on the teaching of vocal music in colleges and universities, combined with the advantages of multimedia technology, you can class the contents of the classroom teaching or video transmission to the students, so that can achieve the extension of vocal classroom teaching. Students in the class time in accordance with their own voice in the classroom to practice will be their own as a reference, you can effectively find their own problems and problems, the students in the classroom learning the feeling of a long time to save, so as to help themselves more accurate grasp of the music to deal with ways to enhance students' vocal performance.

Be Able to Introduce Style Music Teaching to Vocal Music Teaching. In the teaching of traditional vocal courses in colleges and universities, teachers are basically based on a single piano accompaniment, this teaching methods both favorable place, but also have inadequate places, the advantage is that piano teaching can be adapted to students subjective treatment [4]. One of the shortcomings is that the piano itself has a pitch problem, and the piano accompaniment with the rhythm phenomenon, cannot give students an accurate sense of rhythm and style of training. Then the use of multimedia technology in the teaching of vocal music courses can be done in advance of the accompaniment of music can be more prominent music rhythm and style, to help students build a strong rhythm ideas and style concepts, in order to achieve the accuracy of musical expression to enhance students' ability to express their songs. In addition, in the teaching of vocal music in colleges and universities combined with multimedia technology teaching, multi-sound music 
education can be introduced into the vocal classroom teaching, so that students in the vocal singing practice process, but also to accept the multi-concert mode of training, the real effective students to enhance the vocal singing level.

Provide a Viable Teaching Path for Vocal Classroom. In the traditional vocal music teaching, teachers are usually using one-on-one teaching and then this way of teaching, teachers need to take up a lot of classroom time, resulting in the efficiency of the entire classroom teaching is very low. And in recent years, Chinese higher education work more and more popular, the number of classes teaching more and more, colleges and universities in order to ease their own teacher pressure, usually will increase the number of students in the class, and this will inevitably compress teachers teaching content, reduce the quality of college teaching [5]. Therefore, in the process of teaching vocal music in colleges and universities, it is effective to combine the multi-media teaching methods so that the students of the class can adhere to the one-to-one teaching methods and help the students to master the vocal music skills, such as targeted vocal works performance, etc., can use multimedia technology for teaching, multimedia technology, for students to see more, listen, and practice to provide a good basis for protection.

\section{The Use Strategy of Multimedia Technology in the Teaching of Vocal Music in Colleges and Universities}

Optimize the Concept of Music Teaching. In the process of teaching in today's colleges and universities, we do not pay much attention to the education of vocal music. In the face of the current knowledge economy, the vocal education of colleges and universities needs to be transferred from the examination-oriented education to the quality education in order to cultivate the comprehensive development of innovative talents. At present, the reform and innovation of music education in colleges and universities is an important development direction. At present, vocal music teaching in colleges and universities needs to constantly optimize their own curriculum system, get rid of music education single, narrow music vision and backward teaching methods and other issues [6]. Nowadays, the curriculum of music education in colleges and universities in our country is facing the reform stage. In the future, music education in domestic colleges and universities will be gradually integrated with international music education, and the teaching system of world music culture will be established, and the representative culture music and music practice will gradually and the world music course commutation trend. And to establish a multi-disciplinary-based comprehensive education system to ensure that students can learn their own music knowledge and skills and the world to establish a close contact, so as to transcend the traditional simple music teaching and creative activities, the real realization of the students' comprehensive development. The realization of these contents requires colleges and universities in the vocal music teaching process, and actively with the development of modern science and technology to contact students for the establishment of modern music education environment and learning resources system to ensure that college vocal education can better promote the development of all students.

Build a New Type of Music Education. Due to the current development of teaching technology, especially the extensive application of network and computer system, the teaching of music in colleges and universities has produced the change of teaching system. The development of new teaching technology is more efficient and rich in teaching, which can improve students' innovation awareness and ability to cultivate students 'ability to think independently, and realize the comprehensive development of students' comprehensive quality [7]. At present, colleges and universities are very enthusiastic about the development of modern educational technology. Many colleges and universities have increased their investment in network construction. However, if teachers are required to avoid the process of multimedia technology, application software, we should pay attention to actively build a new model of quality education with innovation as the core. In the new vocal music teaching mode, we should pay attention to the development of students' ability of autonomous learning, application and creation. Therefore, teachers should continue to play the main role of students in the teaching of vocal education in our country. At the same time, So that students from the knowledge recipients into active participants and innovators. 
The Environment is an Important Condition in the Use of Multimedia Teaching. In addition, the combination of multimedia technology to carry out vocal music teaching, you need multimedia computer, digital audio card, microphone, monitor the speaker, the music system, and the corresponding digital audio software and other hardware facilities [8]. For the external environment, as long as the requirements of a relatively independent of the room, the impact of the recording is not too much, it should be noted that the microphone and monitor the choice of speakers, you can try to choose some relatively high quality equipment, in such a way, effectively guarantee the fidelity of the student's voice. In addition to the requirements of college vocal teaching teacher, not only have a higher professional quality, but also skilled audio software operation skills and other related equipment operation level, so as to better improve the efficiency and quality of vocal music teaching, Comprehensive and comprehensive development.

Change the Abstract for the Specific Purpose of Multimedia Teaching. The traditional way of vocal music teaching is more abstract, teachers will be multimedia technology and vocal music teaching effective combination, we can fully play the advantages of multimedia technology, vocal music teaching can become more intuitive, such as vocal music teaching and pronunciation organs can be combined with multimedia technology, in the form of pictures or animation to show, so that students can at a glance [9]. In the actual vocal music teaching process, often found that students clearly singing is not standardized, but still feel good self-phenomenon, which is due to their own voice is a bone conduction, one is the air conduction, the audience heard the sound is through When the air to carry the conduction, and students hear their own voice, is transmitted through the air over, so that students will not be aware of their own singing defects. So teachers in this case can be fully combined with the advantages of multimedia technology, students vocal music recording, let the class students to record the recording and evaluation, through this way so that students themselves can accurately recognize their own Lack of, but also to allow other students to find the strengths of others, so as to better promote the overall development of class students.

\section{Conclusion}

In short, in the current efficient vocal teaching process, the effective combination of multimedia technology, can really promote the innovation and development of vocal music teaching, so that students can more active learning music knowledge, so as to effectively improve the efficiency and quality of music teaching in colleges and universities, realizing the modernization of music education in colleges and universities.

\section{Acknowledgements}

Fund Project: The Project of Cultivating the Outstanding Young Key Teachers of "Blue - blue Project" in Colleges and Universities.

\section{References}

[1] Li Lanjun. Multimedia technology in college vocal music teaching in the use and role[J]. Popular arts, 2013, 17: 226.

[2] Zhang Kedong. Multimedia technology in the use of vocal music teaching and the role[J]. Drama House, 2016, 03: 161.

[3] Zhuang Hongzi. On the organic integration of multimedia technology and college vocal music teaching[J]. Journal of Lanzhou Education College, 2012, 08: 118-119 + 141.

[4] Liu Guofeng, Ning Hongmei. Vocal music teaching in the integration of the application and teaching methods analysis[J]. China Management Information, 2017, 12: 224-225.

[5] Cheng Yun.Discussion of multimedia technology in college piano teaching application[J]. Yellow River Voice, 2017, 09: 35-36. 
[6] Ma Ling. Modern multimedia technology in the current vocational vocal music teaching in the use of analysis [J]. Drama House, 2014, 17: 261-262.

[7] Deng Juxun. College of vocal music teaching multimedia application skills[J]. Big stage, 2015, 06: 186-187. 